\title{
Evaluation of the Satisfaction Metrics used by Stakeholders on Large Engineering Projects
}

\author{
Abimbola Windapo ${ }^{1}$ and Gcinulwazi Qamata ${ }^{2}$ \\ ${ }^{1}$ Senior Lecturer, Department of Construction Economics and Management, University of Cape Town, Lovers Walk, \\ Rondebosch, 7701, South Africa, E-mail: abimbola.windapo@uct.ac.za (corresponding author). \\ ${ }^{2}$ Project/Contracts Manager, Eskom-Generation, Johannesburg, South Africa, E-mail: QamataG@eskom.co.za
}

Project Management

Received January 14, 2015; received revision May 20, 2015; accepted May 27, 2015

Available online June 25, 2015

\begin{abstract}
This paper examines stakeholder perspectives on the use of satisfaction metrics in large engineering projects and asks whether there is a significant difference in the perception of the stakeholders on the use of satisfaction metrics. The rationale for the examination stems from the view by scholars that difficulty experienced by project managers on projects is as a result of the different perception of project performance criteria within the stakeholder group. The study makes use of existing literature in identifying the satisfaction metrics used by stakeholders on construction projects. A mixed method research approach incorporating both objective and subjective paradigms was used in the study to collect empirical data from stakeholders working on four large construction sites being procured by a South African State Owned Company (SOC). The data was collected using a structured questionnaire and focused group interviews. The study established that there are significant differences in the views of participants on important satisfaction metrics. The level of use of this form of success criteria was found to be more important to the client followed by the consultants engineers and architects, while the project management team perceived it as being of less importance. The paper recommends that clients of large engineering projects should put in place strategies that will bring about explicit communication between the different stakeholders and an avenue for softening the boundary relationships that may exist between them. The research conducted is restricted to one SOC in South Africa and its four sites. Non-disclosure by the SOC of the performance of the projects under construction also brought about difficulties. Therefore, future research, which would explore the validity of these research findings with another comparable SOC project, is recommended.
\end{abstract}

Keywords: Large engineering projects, perception, project success and satisfaction.

\section{Introduction}

The construction industry is project-based and no two projects are exactly the same. Projects differ in terms of requirements, complexities and are surrounded with uncertainties which make it difficult to manage and satisfy stakeholders (Loosemore, 2006). Projects require planning and efficient management of its stakeholders to be successful and satisfaction of stakeholders' needs is key to achieving desired outcomes (Bourne, 2006). Globally, most public and private organisations implement their strategic objectives using the project management approach (Burke, 2011; Nicholas, 2008); this is also the case in South Africa. However, research has shown that this approach makes it difficult for project management practitioners and researchers to have a standard measure of project success (Griffith et al., 1999). What makes the concept of project success difficult and complicated in practice is because stakeholders have conflicting interests and goals (Hillman and Klein, 2001), which according to Frödell et al. (2008) results in different perceptions of success and in the different ways of measuring success.
Traditionally, projects' success was tied to the three criteria of meeting the cost, schedule and quality of projects (Navarre and Schan, 1990; Belassi and Tukel, 1996; Hatush and Skitmore, 1997; Shenhar et al., 1997; Atkinson, 1999). In construction today, successful projects cannot only be viewed from the angle of meeting the three criteria but also in meeting stakeholders' satisfaction (Atkinson, 1999). Al-Otaibi et al. (2013) identified 14 critical success factors deemed collectivelyy to have a significant impact on the process of improving project performance. Cooke-Davies (2002) posits that success criteria is the measure by which success or failure of a project will be judged. Though, stakeholder satisfaction depends on information concerning the three success criteria of time, cost and quality combined with accuracy and reliability of the data and information (Nguyen et al., 2009).

To meet these requirements, project organisations are becoming more sophisticated and several approaches have been instituted to deliver construction projects on schedule, to cost and meet the desired quality (Toor and Ogunlana, 2009). In addition, Lim and Mohammed (1999) and Toor 
and Ogunlana (2010) acknowledge that different stakeholders perceive project success differently resulting in diverse criteria in terms of judging success. However, in spite of these developments all types of projects still experience high degrees of failure (Bourne, 2006; Investment Monitoring Report, 2012). It is however not known whether this failure is linked to how a stakeholder views satisfaction on projects which is subjective and their use of objective measures of satisfaction.

This paper thus examines the perception of project stakeholders on the satisfaction metrics used in measuring project success on four large infrastructure projects procured by a State Owned Company (SOC) in South Africa. It also examines whether there are significant differences in the perception of stakeholders' on the performance metrics used. The rationale for this study is hinged on the fact that project success or failure is measured based on how well the product meets the expectations of the stakeholder and their perceived value of the project (Al-Tmeemy et al., 2011). However, over the decades the construction industry has been singled out to have a poor record of satisfying stakeholders' owing to its fragmented nature (Egan, 1998; Loosemore, 2006). Many of these problems stem from inadequate engagement of stakeholders, lack of clarity on measures of stakeholder management, poor communication among stakeholders and the challenges of identifying "invisible" stakeholder (Yang et al., 2009). This study therefore, argues that identifying common metrics for measuring satisfaction will provide knowledge that would aid the delivery of projects that gratifies all stakeholders and advance the need to soften the boundary relationship that may exist between stakeholders so as to achieve successful delivery of construction projects.

\subsection{Research Proposition and Objective}

The main proposition for this study is that project stakeholders' will have different perception of project satisfaction metrics which can be influenced by identifying and prioritising the metrics. In order to test this proposition, this paper examines the major metrics consisting of both subjective and objective success metrics which can help in drawing more discerning conclusions about a project's success. The study therefore has the potential to offer a means of identifying project satisfaction metrics perceived as important by the different stakeholders on large engineering projects so that stakeholders can agree on these at the beginning of the project.

\section{Overview of Stakeholder Satisfaction}

\subsection{Identifying Stakeholders}

In order to satisfy stakeholders, it is essential to identify who the stakeholders are on a project, what are their interests and develop means of meeting their expectations (Nguyen et al., 2009). A stakeholder can be defined as an individual or group of individuals that can heavily influence the success or failure of a project. These categories of people, in turn, have certain expectations from the project, and examining the extent to which these expectations are currently being satisfied in a balanced fashion provides a valuable metric of project success (Curtice, 2006).

Different approaches of identifying stakeholders have been used in literature, for example, French and Granrose
(1995) applied mutuality approach which is a way of understanding the requirement of each stakeholder on a project plus the importance of the stakeholder to the project. This will assist in establishing the nature of the association between the stakeholders and project and as well guarantee that project managers comprehend the expectation of the categories. According to Pinto (1998) the project stakeholders can be categorised into different types based on various criteria such as those that have direct impact on the project, those indirectly affected and the group with most influence from either category. This study categorises stakeholders into project team, project sponsor/client and consultants. According to Chan and Chan (2004), stakeholders must be satisfied with the overall performance of the project.

\subsection{Stakeholder Perceived Success Metrics}

A metric is any type of measurement used to assess some quantifiable element of project success or performance. The saying that you cannot manage what you cannot measure is a truism in construction project. Absence of satisfaction metrics can make it extremely difficult for project managers to assess the satisfaction of stakeholders. Stakeholders' interests vary as a result of the complex nature of construction projects and it is a common belief that identifying stakeholder interests and expectations is an important task in evaluating stakeholders' satisfaction (Cleland and Ireland, 2007; Freeman et al., 2007).

Previous research has shown the significance of subjective metrics as determinants of construction project success, despite the complexity involved in their measurements (Hughes et al., 2004). For instance, Baker et al. (1974 cited in Hughes et al., 2004: 32) argued that if the project meets the technical expectation specifications and/or mission to be performed, and if there is a high level of satisfaction concerning the project outcome among key stakeholders in the parent organisation, client organisation, project team, and key end users of the project effort, the project is considered an overall success. They contend further that since stakeholders' perceptions play such a significant role in considering the project a success, then it is more appropriate to view it in terms of "perceived success of a project."

Although, success of project has been measured objectively in the past, but objective project metrics cannot offer a comprehensive story concerning project success without an explanation of the context in which the project success attributes were perceived (Hughes et al., 2004). Also, subjective metrics of project success are considered to be only important when viewed from the angle of a specific observer, this is because project success are perceived differently by different project stakeholders and thus, it essential to make clear the point of view at which the subjective success metric is being measured (Hughes et al., 2004). Researchers contend that a wrong conclusion regarding project success could be drawn by project analysts if they only considered the traditional project success metrics (cost, time, quality, and more recently, safety) while disregarding subjective success metrics (Nguyen et al., 2009; Hughes et al., 2004; Abdullah and Ramly, 2006), such as satisfaction.

According to Abdullah and Ramly (2006), overall stakeholder appreciation (satisfaction) of the project is the major determinant of project success, as this would have the advantage of the stakeholder being prepared to 
overlook schedule and cost over-runs, delays and other requirements. Lim and Mohammed (1999) posit that project success should be viewed from different perspectives such as individual, client, user and other stakeholders. Two categories: the macro and micro viewpoints were suggested in their study. The micro view point drawing from the perspectives of the individual client and end-user looks into the overall picture of the project and determines if the original project concept is satisfied. On the other hand, the micro viewpoint of project success based on the perspectives of the contractor, consultant and other project personnel, deals with project achievement in smaller component levels such as fulfilment of technical requirements and completion within time, budget and quality. Fig. 1 shows the project satisfaction metrics used in the study, based on the project sponsor/client and the project team/consultant perspectives.

According to Shenhar et al. (1997) client satisfaction is composed of four factors: fulfilling client needs, solving major operational problems, the use of the product by the customer, and the level of customer satisfaction. However Shenhar et al. (1997) posit that project success criteria such as meeting the project specifications and quality standards have an impact on overall client satisfaction in the project. This is aligned to the view of Westerveld (2002) that satisfaction ensues when the individual user and stakeholder is happy with the functionality of the end product, and project outcomes. Therefore, this research used the following four satisfaction metrics in measuring stakeholders' perceived satisfaction in a construction project - fulfilment of (client and technical) requirements, execution efficiency, compliance to regulations and overall completion of projects within time, budget and quality.

There is a dearth of literature on the measures of stakeholder satisfaction on construction projects. Previous researches on satisfaction metrics focus on businesses and customer satisfaction (Kaplan and Norton, 1995; and ElMashaleh et al., 2007); software customer satisfaction metrics of capability, usability, performance, installability, reliability, availability, maintainability and documentation (Balm, 1996); incorporation of satisfaction metrics into the context of design formulations (Chen, 2000); and healthcare (Weissman et al., 2010).

\section{Research Methods}

The focus of this study is on a State Owned Company (SOC), which was established by the government of the Cape, South Africa in 1928 with the purpose of creating an enabling environment for the development and sustainability of the economy through energy supply. Over the past decades, the SOC has undertaken some capital expansion projects through the construction of large new infrastructure so as to meet its objectives in rising to the challenges of the growing South African economy. The authors consider the SOC to be a suitable setting for this research for the following reasons: (a) it is engaged in construction projects, which are intended to benefit the public; (b) its performance can be used to benchmark other SOC construction projects; and (c) the construction projects undertaken is unequalled in terms of values for the past five decades in South Africa.

In order to obtain relevant data and meaningful results for the research, this study adopts a sequential mixed method approach, which involves the collection and analysis of qualitative and then quantitative data within one study. According to Tashakkori and Teddlie, (1998) and Creswell (2005), mixed methods research design is a method for collecting, analysing, and "mixing" or integrating both quantitative and qualitative data at some stage of the research process within a single study for the purpose of gaining a better understanding of the research problem. However, in this study mixed methods was used whereby qualitative data were first collected to refine the questionnaire before administering same.

The sample for the focus group interview were drawn from four major construction sites considered in this research using a purposive sampling technique (Noor, 2008) from a population of construction project practitioners (SOC Management, Funding Organization, Project/Contracts Managers, Project Supervisors, Contractor Site Managers, Construction Managers, Project Sponsors, and Project Support Managers). The purposive sampling technique was used because knowledge of the project operations was not normally distributed within the target population. These construction project practitioners were perceived by the authors to be able to contribute valuable information to the research. The list of construction project practitioners to be surveyed was obtained from the SOC database, using a random sampling technique. Questionnaires were self-administered to 92 selected construction project practitioners including contractors on the sites from July 2012 to January 2013 (a six month period). Fig. 2 shows the flow of the research framework used in this study.

In order to elicit relevant information on the perception of the stakeholders on project satisfaction metrics, the respondents were requested to rank the metrics on a fivepoint Likert scale, where $1=$ strongly disagree/low and 5 = strongly agree/high. Mean statistics (MS) see Eq. (1), were used in analysing and rating the data obtained from the questionnaires so as to establish common trends and differences amongst the respondents on each project success metric.

$$
M S=\frac{5 \mathrm{M} 5+4 \mathrm{M} 4+3 \mathrm{M} 3+2 \mathrm{M} 2+1 \mathrm{M} 1}{(\mathrm{M} 5+\mathrm{M} 4+\mathrm{M} 3+\mathrm{M} 2+\mathrm{M} 1)}
$$

(Where: $\mathrm{M}_{1}=$ strongly disagree; $\mathrm{M}_{2}=$ disagree; $\mathrm{M}_{3}=$ somehow agree; $\mathrm{M}_{4}=$ agree; and $\mathrm{M}_{5}=$ strongly agree) 


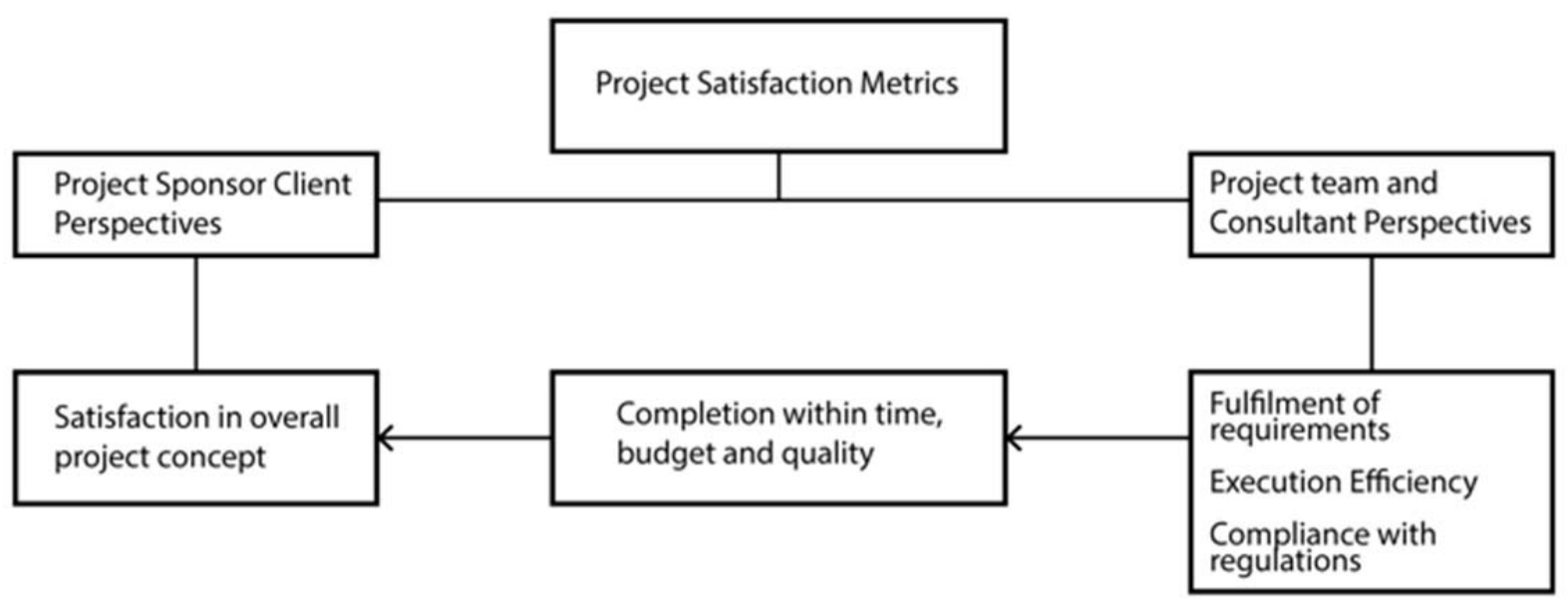

Fig. 1. Project satisfaction metrics (after Shenhar et al., 1997; Lim and Mohammed, 1999; and Westerveld, 2002)

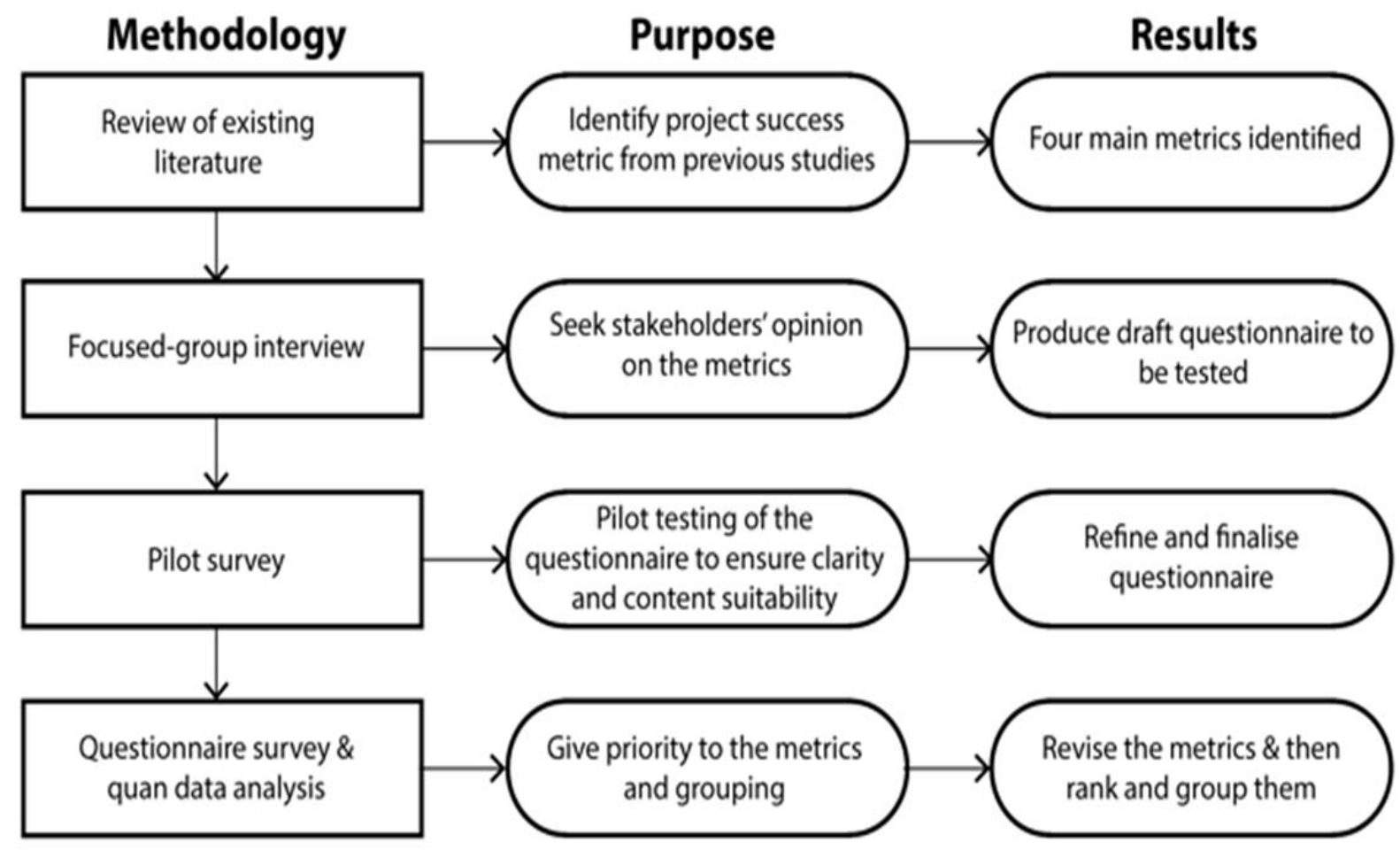

Fig. 2. Research framework (adapted from Yang et al., 2009)

To examine whether there is a significant difference in the perception of stakeholders on the metrics of project success, non-parametric statistical technique was employed. This is because parametric assumptions requiring data to be normally distributed and homogenous in terms of variance are not fulfilled (Pallant, 2011), and since these assumptions were not fulfilled by survey data, the non-parametric methods was used. The research used Pearson Chi square statistics (Using $\mathrm{R}$ software) in examining whether there are significant differences in the perception of the project stakeholders regarding success metrics. The results of this test were interpreted in terms of goodness-of-fit test. The probability associated with the chi square statistic indicates whether or not there is a significant difference in the perception of the stakeholders on the metrics of project success. If the probability is significant at $5 \%$ level, this means there is significant differences in their perceptions. The research findings may be constrained by the fact that the available archival documents for the projects were not sufficiently explicit and comprehensive in providing details of the existing objective project success metric.

\section{Results and Discussion}

Data collected from the empirical survey are presented in the following sections:

\subsection{Distribution of Stakeholders by Project Sites and Groups}

Table 1 shows the profile of the respondents in this research. The highest number of respondents by group is the project supervision team, which comprises of engineers and project managers who oversee the construction of the large engineering projects on behalf of 
the client. Designated project managers who are in charge of the individual project sites and who are employees of the SOC constitute the second highest respondents in the study. Table 1 also indicates that the highest numbers of respondents were from Site 4 followed by Sites 3, 2 and 1 respectively.

\subsection{Level of Performance achieved on the SOC Large Engineering Project Sites}

Secondary data is used in evaluating the level of performance of the SOC projects. Performance of these projects is viewed in both financial - cost and none financial - time terms. The cost and time performance of the SOC projects studied are presented in Table 2.

Table 2 shows that apart from Site 3, all other sites are still operating within the budget allocated and that these projects are at different stages of completion with Site 3 being at the most advanced stage of completion and
Project 1 still to take-off. Table 2 also reveals that there will be a need to extend the budget allocation made to Site 3 , and that the target completion time on all these SOC project sites has not been met. Site 2 emerged as the worst site in terms of time performance followed by Site 3 .

\subsection{Perception of Client and Stakeholder Satisfaction in Projects}

Table 3 shows the level of stakeholder satisfaction in the construction projects distributed according to the project sites.

The respondents perceived that the client, project team stakeholders and consultants are least satisfied with Site 2 and more satisfied with Site 4. This result is aligned with the objective data presented in Table 2 and suggests that completion within time and budget may result in the satisfaction of the project stakeholders in the overall project.

Table 1. Distribution of respondents by project and group

\begin{tabular}{|c|c|c|c|c|c|c|}
\hline \multirow{2}{*}{ Stakeholder Group } & \multicolumn{4}{|c|}{ Engineering project sites } & \multirow{2}{*}{ Total } & \multirow{2}{*}{ Percentage $(\%)$} \\
\hline & 1 & 2 & 3 & 4 & & \\
\hline Project supervisors & 10 & 9 & 10 & 10 & 39 & 42.4 \\
\hline Project managers & 4 & 4 & 4 & 4 & 16 & 17.4 \\
\hline Contractor representatives & 2 & 3 & 2 & 3 & 10 & 10.9 \\
\hline Client (SOC) & 2 & 2 & 3 & 3 & 10 & 10.9 \\
\hline Consultants & 2 & 2 & 3 & 2 & 9 & 9.8 \\
\hline Project sponsor/financier & 1 & 2 & 2 & 3 & 8 & 8.7 \\
\hline Total & 21 & 22 & 24 & 25 & 92 & 100 \\
\hline
\end{tabular}

Table 2. Quantitative level of project performance

\begin{tabular}{cccccc}
\hline \multirow{2}{*}{ Sites } & \multirow{2}{*}{$\begin{array}{c}\text { Overall budget (Billions of } \\
\text { Rand) }\end{array}$} & & \multicolumn{2}{c}{ Expenditure (Billion Rand) } & \multicolumn{2}{c}{ Percentage completion } \\
\cline { 3 - 6 } & 180 & Budget & Actual & Planned & Actual \\
\hline 1 & 310 & 12.3 & 0.8 & N/A & 7.0 \\
2 & 425 & 53.6 & 48.5 & 32.5 & 17.6 \\
3 & 518 & 76.9 & 79.1 & 61 & 52 \\
4 & & 85.9 & 74.8 & 59.4 & 52 \\
\hline
\end{tabular}

Key: R1 = USD 11 
Table 3. Perceived level of client and stakeholder satisfaction distributed according to sites

\begin{tabular}{|c|c|c|c|c|c|c|c|}
\hline \multirow{2}{*}{ Sites } & \multicolumn{5}{|c|}{ Level of client satisfaction-where $1=$ low and $5=$ high } & \multirow{2}{*}{ MS } & \multirow{2}{*}{ Rank } \\
\hline & 1 & 2 & 3 & 4 & 5 & & \\
\hline 4 & - & - & 1 & 1 & 22 & 4.88 & 1 \\
\hline 3 & - & - & 1 & 6 & 18 & 4.68 & 2 \\
\hline 1 & - & 2 & 2 & 10 & 6 & 4.00 & 3 \\
\hline 2 & - & 1 & 8 & 10 & 3 & 3.68 & 4 \\
\hline Total & - & 3 & 12 & 27 & 49 & 4.34 & \\
\hline \multirow{2}{*}{ Sites } & \multicolumn{5}{|c|}{ Level of stakeholder satisfaction-where $1=$ low and $5=$ high } & \multirow{2}{*}{ MS } & \multirow{2}{*}{ Rank } \\
\hline & 1 & 2 & 3 & 4 & 5 & & \\
\hline 4 & - & - & 2 & 8 & 15 & 4.52 & 1 \\
\hline 3 & - & - & 1 & 11 & 13 & 4.48 & 2 \\
\hline 1 & - & 1 & 12 & 2 & 5 & 3.55 & 3 \\
\hline 2 & - & - & 14 & 7 & 1 & 3.41 & 4 \\
\hline Total & - & 1 & 29 & 28 & 34 & 4.02 & \\
\hline
\end{tabular}

\subsection{Rating of Project Satisfaction Metrics}

The analysis of the questionnaire survey response was used to generate the means for the 4 main project satisfaction metrics identified in literature. The ranking and the mean values for the success metrics are shown in Table 4.

Table 4. Descriptive statistics

\begin{tabular}{ccc}
\hline Satisfaction metric & MS & Rank \\
\hline Execution efficiency & 4.60 & 1 \\
Fulfilment of requirements & 4.55 & 2 \\
Compliance to regulations & 4.55 & 2 \\
$\begin{array}{c}\text { Completion of project within } \\
\text { schedule }\end{array}$ & 4.50 & 4 \\
\hline
\end{tabular}

It was found out that the means of the metrics ranged from 4.50 to 4.60 , which shows that all respondents consider these 4 attributes relevant in satisfying stakeholder expectations and meeting their requirements in construction projects. The highest ranking by all respondents was "execution efficiency" (mean $=4.60)$, which therefore was considered as an extremely significant metric in measuring the success of projects and satisfaction of stakeholders. "Fulfilment of (clients/project sponsors and technical) requirements and compliance to regulations" (mean $=4.55$ ) were both ranked as the second most important metrics. The $4^{\text {th }}$ ranked metric was "completion of project within schedule" (mean $=4.50)$.

\subsection{Perceptions of Stakeholders on Project Satisfaction Metrics}

In order to examine whether there were significant differences in the perception of stakeholders on the metrics used in measuring project satisfaction, the Chi square statistics was used. Table 5 shows the Chi square statistics of the four metrics used in the study.

The Chi-square goodness-of-fit test presented in Table 5 indicates that there was significant difference in the perception of stakeholders on execution efficiency as measures of project satisfaction when compared with the other metrics $\chi^{2}(1, n=92)=31.4403, \quad p<.05$. These statistical results indicate a general consensus on the perception of the different stakeholders' on the use of "fulfilment of (client and technical) requirements, completion of the project within schedule and compliance with regulations as project satisfaction metrics."

\subsection{Discussion of Findings}


Findings from the survey data through ranking suggest that execution efficiency and effectiveness is the most influential metrics of project success and stakeholder satisfaction. The result also reveals that fulfilment of (client and technical) requirements and compliance to regulation are essential in measuring project satisfaction. These findings are consistent with Torbica and Stroh (2001), assertion that meeting client's need is one of the success criteria frequently used in measuring satisfaction on construction projects, and is supported by Prabhakar (2008) who argues that these metrics have an impact on stakeholder's satisfaction, such as meeting functionality requirements and quality standards. This is confirmed by the study findings, which suggests that project stakeholders are more satisfied with the overall project concept if it is complete within scheduled time and budget. These criteria are influenced by the satisfaction metrics of requirement fulfillment, efficient execution and compliance with regulations. Chan et al. (2001) state that these subjective metrics of project satisfaction form the basis for fulfilling individual stakeholder expectations. This position is re-affirmed by Takim and Adnan (2008) who assert that quality and meeting client's need are the most significant measures of project success.

The results of the non-parametric analysis indicate that there is no significant difference in the perception of stakeholders on project satisfaction metrics except in terms of execution efficiency. Therefore, it can be said that the finding do not lend credence to the proposition that that there will be significant differences in the perception of stakeholders on the measure of project satisfaction metrics. This implies that data collected in this study does not support the view that there may be significant differences in perceptions within the stakeholders groups working on the four SOC projects studied on measures and use of project satisfaction metrics. The findings do not also resonate the view of previous researchers who found significant differences in the opinion of stakeholders on project success criteria (for example Hillman and Klein, 2001; Wang and Huang, 2006; Toor and Ogunlana, 2010). This results may be due to the fact that the SOC is experienced in implementing large construction projects and it has in place documented procedures, standards and processes which it uses on its projects and hands these out to its employees and service providers to use as reference in project implementation.

\section{Conclusions and Recommendations}

This paper examines stakeholder perspectives on the use of satisfaction metrics in large engineering projects and whether there are significant differences in their perceptions in the use of satisfaction metrics on projects. The study found that the stakeholders rated the identified satisfaction metrics very high, and fulfillment of (client and technical) requirements was rated the highest. The study also established that there was a significant difference in the perception of stakeholders on the use of fulfilling project requirements as a project satisfaction metric while these perceptions did not differ on the use of the other identified satisfaction metrics. Based on these findings, the study concludes that the difficulty experienced on projects especially large engineering projects and the high degree of failure may be traced to the differing views of stakeholders in the use of fulfilling project requirements as a project satisfaction metric. It can also be concluded that project stakeholders tend to be more satisfied with projects that are completed within scheduled time and budget.

Evidence from literature indicates that it is essential that stakeholders at the commencement of the project ensure they have a common insight into how project success will be determined and that stakeholders especially clients must be satisfied with the overall project performance. However, the research is limited in scope to one SOC in South Africa and its four project sites and this affects the generalizability of the results even though it provides significant results. Non-disclosure by the SOC of the performance of the projects under construction also brought about limitations. The study could not compare the subjective data obtained to the objective data gathered by the SOC in the area of compliance to regulations and quality requirements. Therefore further research which would explore the validity of these findings with another comparable SOC project and context is recommended.

\section{Acknowledgements}

The authors acknowledge the support provided by Dr. Luqman Oyewobi and Mr. Sunday Odediran in the preparation of this paper.

Table 5. Pearson's Chi-square results of stakeholders' perception

\begin{tabular}{|c|c|c|c|}
\hline \multirow{2}{*}{ Metric } & \multicolumn{3}{|c|}{ Test statistics } \\
\hline & $X^{2}$ & $d f$ & P-Value \\
\hline Fulfilment of requirements & 4.8913 & 10 & 0.8983 \\
\hline Execution efficiency & 31.4403 & 20 & 0.0496 \\
\hline $\begin{array}{l}\text { Completion of the project } \\
\text { within schedule }\end{array}$ & 2.6748 & 10 & 0.9881 \\
\hline Compliance to regulations & 3.2516 & 5 & 0.6613 \\
\hline
\end{tabular}




\section{References}

Abdullah, W. M. W. and Ramly, A. (2006). Does successful project management equate to project success? Proceedings of the International Conference on Construction Industry (ICCI '06), Universiti Teknologi Malaysia, Malaysia.

Al-Otaibi, S., Osmani, M., and Price, A. D. F. (2013). A framework for improving project performance of standard design models in Saudi Arabia, Journal of Engineering, Project, and Production Management, 3(2), 85-98.

Al-Tmeemy, S. M., Abdul-Rahman, H., and Harun, Z. (2011). Future criteria for success of building projects in Malaysia, International Journal of Project Management, 29(3), 337-48.

Atkinson, R. (1999). Project management: cost, time and quality, two best guesses and a phenomenon, its time to accept other success criteria, International Journal of Project Management, 17(6), 337-42.

Baker, B. N., Murphy, D. C., and Fisher, D. (1974). Determinants of Project Success. National Technical Information Services, N-74-30392 (Sept. 15, 1974).

Balm, G. J. (1996). Benchmarking and gap analysis: what is the next milestone? Benchmarking for Quality Management and Technology, 3(4), 28-33.

Belassi, W. and Tukel, O. I. (1996). A new framework for determining critical success/failure factors in projects, International Journal of Project Management, 14(3), 141-51.

Bourne, L. (2006). Project relationship and the stakeholder circle. Paper presented at the Project Management Institute research conference, 16-19 July, 2006. Centre Mont-Royal, Montreal, Canada.

Chan, A. P. C. and Chan, A. P. L. (2004). Key performance indicators for measuring construction success, Benchmarking: An International Journal, 11(2), 203-221.

Chan, A. P. C., Ho, C. D. K., and Tam, C. K. (2001). Design and Build Project Success Factors, Journal of Construction Engineering and Management, 127(2), 93-100.

Chan, L. (2000). Multiobjective design optimization based on satisfaction metrics, Engineering Optimization, 33(5), 601-617.

Cleland, D. I. and Ireland L.R. (2007). Project Management: Strategic Design and Implementation. 5th ed. New York: McGraw-Hill.

Creswell, J. W. (2005). Educational research: Planning, conducting, and evaluating quantitative and qualitative approaches to research. 2nd ed. Upper Saddle River, NJ: Merrill/Pearson Education.

Curtice, R. M. (2006). Stakeholder Analysis: The Key to Balanced Performance Measures. Retrieved from: http://www.bptrends.com/publicationfiles/04-06-WPStakeholderAnalysis-Curtice.pdf. on August 18, 2014.

Egan, J. (1998). Rethinking Construction, Department of the Environment, Belfast.

El-Mashaleh, M.S., Edward Minchin Jr, R., and O'Brien, W. J. (2007). Management of construction firm performance using benchmarking, Journal of Management in Engineering, 23(1), 10-17.

Freeman, R. E., Harrison, J. S., and Wicks, A. C. (2007). Managing for Stakeholders-survival, reputation and Success. US: Louis Stern Memorial Fund.

French, W. A. and Granrose, J. (1995). Practical business ethics. Englewood Cliffs, NJ: Prentice Hall.
Frödell, M., Josephson, P., and Lindahl, G. (2008). Swedish construction clients view on project success and measuring performance, Journal of Engineering, Design and Technology, 6(1), 21-32.

Hatush, Z. and Skitmore, M. (1997). Evaluating contractor prequalification data: selection criteria and project success factors, Construction Management and Economics, 15(2), 129-47.

Hillman, A. J. and Klein, G. D. (2001). Shareholder Value, Stakeholder Management, and Social Issues: What's the Bottom Line? Strategic Management Journal, 22(2), 125-139.

Hughes, S. W., Tippett, D. D., and Thomas, W. K. (2004). Measuring Project Success in the Construction Industry. Engineering Management Journal, 16(3), 31-37.

Investment Monitoring Report - State Owned Company (SOC). (2012). August, South Africa: Eskom.

Kaplan, R. S. and Norton, D. P. (1995). Putting the balanced scorecard to work. Performance measurement, management, and appraisal sourcebook, 66.

Loosemore, M. (2006). Managing project risks, in: The management of complex projects: a relationship approach, Prykes, S. and Smith, H. UK: Blackwell, 187-204.

Nguyen, N. H., Skitmore, M., and Wong, J. K. W. (2009). Stakeholder impact analysis of infrastructure project management in developing countries: a study of perception of project managers in state-owned engineering firms in Vietnam. Construction Management and Economics, 27(11), 1129-1140.

Navarre, C. and Schaan, J. L. (1990). Design of project management system from top management perspective, Project Management Journal, 21(2), 1927.

Noor, K. B. M. (2008). Case Study: A Strategic Research Methodology, American Journal of Applied Sciences, 5(11), 1602-1604.

Pallant, J. (2011). SPSS Survival Manual: A Step by Step Guide to Data Analysis using SPSS for Windows, 3rd Edition, Open University Press. McGraw Hill, New York, NY.

Pinto, J. K. (1998). Project Management Handbook. San Francisco, California: The Project Management Institute Jossey-bass Inc.

Prabhakar, G. P. (2008). What is Project Success: A Literature Review. International Journal of Business and Management, 3(9), 3-10.

Shenhar, A. J., Levy, O., and Dvir, D. (1997). Mapping the dimensions of project success, Project Management Journal, 28(2), 5-13.

Takim, R. and Adnan, H. (2008). Analysis of Effectiveness Measures of Construction Project Success in Malaysia. Asian Social Science, 4(7), 7491.

Tashakkori, A. and Teddlie, C. (1998). Mixed methodology: combining qualitative and quantitative approaches. Thousand Oaks, CA: Sage.

Toor, S. and Ogunlana, S. O. (2009). Construction professionals' perception of critical success factors for large-scale construction projects, Construction Innovation: Information, Process, Management, 9(2), 149-67.

Toor, S. and Ogunlana, S. O. (2010). Beyond the 'Iron Triangle': Stakeholder perception of key performance indicators (KPI) for large-scale public sector 
90 Windapo, A. and Qamata, G.

development projects, International Journal of Project Management, 28(3), 228-236.

Torbica Z. M. and Stroh R. C. (2001). Customer Satisfaction in Home Building. Journal of Construction Engineering and Management, 127(1), 82-86.

Wang, X. and Huang, J. (2006). The relationships between key stakeholders' project performance and project success: Perceptions of Chinese construction supervising engineers, International Journal of Project Management, 24(6), 253-260.

Weissman, D. E., Morrison, R. S., and Meier, D. E. (2010). Center to advance palliative care, palliative care clinical care and customer satisfaction metrics consensus recommendations. Journal of Palliative Medicine, 13(2), 179-184.

Yang, J., Shen, G. Q., Ho, M., Drew, D. S., and Chan, A. P. C. (2009). Exploring critical success factors for stakeholder management in construction projects. Journal of Civil Engineering and Management, 15(4), 337-348.

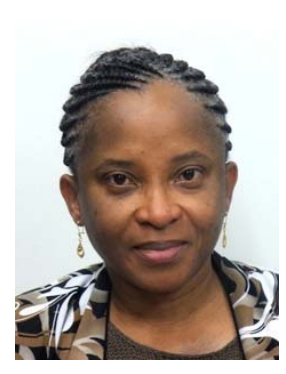

Dr. Abimbola Olukemi Windapo is a Senior Lecturer at the Dept. of Construction Economics and Management, University of Cape Town. She is a Registered Construction Project Manager with the SA Council for the Project \& Construction Management Profession (SACPCMP) and Registered Builder with Council of Registered Builders of Nigeria (CORBON). Her research interests are in the area of construction industry development, business \& project management from a performance $\&$ practice perspective.

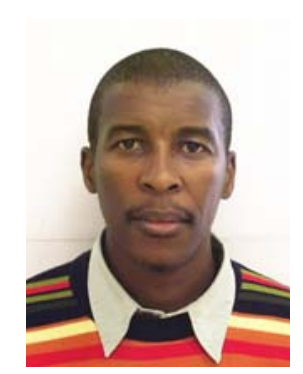

Mr. Gcinulwazi Qamata is a former Project/Contracts Manager at Eskom-Generation Johannesburg Area, South Africa. His research focus is in the area of construction project performance. 